\title{
Identification of Arenes from Shengli Lignite in Toluene/Ethanol Mixed
}

\section{Solvent}

$$
\text { Jun-Zhou }{ }^{1, a^{*}} \text {, Xi-Hua Du }{ }^{1, b} \text {, Mingzhen-Li }{ }^{1, c}
$$

${ }^{1}$ School of Chemical Engineering and Technology, Xuzhou Institute of Technology, Xuzhou, Jiangsu, China

aemail: zhoujunxz@126.com, bemail: dxh@xzit.edu.cn, cemail: 493800728@qq.com

Keywords: Shengli lignite; thermal dissolved; GC/MS analysis; arenes

Abstract: Shengli lignite (SL) was thermal dissolved (TD) in a toluene/ethanol mixed solvent and the dissolved matters was further analyzed with gas chromatography/mass spectrometry (GC/MS). 15 arenes were detected and their structure were identified by GC/MS. The analysis of these high-valued arenes from soluble SL could provide an important theoretical basis for non-fuel of lignite.

\section{Introduction}

With the development of economy, the energy crisis and environmental pollution are becoming more and more serious. So the clean development and fine utilization of coal is paid more and more attention by the experts. In the process of research on the structure of coal, scholars find the coal is rich in aromatic ring and heteratom-containing organic compounds ${ }^{[1]}$, which is a fatal weakness of conversion coal to clean fuel. But it is a new research direction in the field of mineral processing engineering and organic chemical industry. Aromatic ring in coal is also the aromatic polymers and ideal raw material for engineering plastics ${ }^{[2-3]}$, which has strong competitiveness and development prospects of the market.

\section{Experimental section}

The SL, collected from Shengli coal field, Xilinhaote, Inner Mongolia province, China, was pulverized to pass through a 200-mesh sieve followed by desiccation in a vacuum oven at $80^{\circ} \mathrm{C}$ for $24 \mathrm{~h}$. Table 1 lists its proximate and ultimate analyses.

Table 1 Proximate and ultimate analyses (wt $\%$ ) of SL

\begin{tabular}{|c|c|c|c|c|c|c|c|c|}
\hline \multicolumn{3}{|c|}{ Proximate analysis } & \multicolumn{5}{|c|}{ Ultimate analysis(wt \%, daf) } & \multirow{2}{*}{$\mathrm{H} / \mathrm{C}$} \\
\hline $\mathrm{M}_{\mathrm{ad}}$ & $\mathrm{A}_{\mathrm{d}}$ & $\mathrm{V}_{\text {Mdaf }}$ & $\mathrm{C}$ & $\mathrm{H}$ & $\mathrm{N}$ & $\mathrm{S}$ & $\mathrm{O}_{\text {diff }}$ & \\
\hline 12.52 & 16.69 & 43.44 & 74.29 & 4.27 & 1.08 & 1.13 & 19.24 & 0.6850 \\
\hline
\end{tabular}

diff: by difference; daf: dry and ash-free base; $M_{\mathrm{ad}}$ : moisture (air dried base); $A_{\mathrm{d}}$ : ash (dry base, i.e., moisture-free base); $V_{\text {daf: }}$ volatile matter (dry and ash-free base).

$2 \mathrm{~g}$ of dehydrated coal sample and $50 \mathrm{~mL}$ of toluene/ethanol ( $1: 1, \mathrm{~V} / \mathrm{V})$ were placed into a $100 \mathrm{~mL}$ autoclave, reaction for $2 \mathrm{~h}$ at the temperature of $330{ }^{\circ} \mathrm{C}$. The toluene and ethanol of the above 
solution was removed by rotary evaporation under reduced pressure and the TDSL at the bottom of the autoclave was obtained for GC/MS analysis.

The TDSL sample was analyzed by a Hewlett-Packard 6890/5973 GC/MS equipped with a capillary column coated with HP-5MS (crosslink5\% PH MEsiloxane, $30 \mathrm{~m} 25 \mathrm{~mm}$ i.d., $0.25 \mathrm{~mm}$ film thickness)and a quadrupole analyzer and operated in electron-impact $(70 \mathrm{eV})$ mode. The mass range scanned was from 30 to $500 \mathrm{amu}$. The column was heated at a rate of $10{ }^{\circ} \mathrm{C} \cdot \mathrm{min}^{-1}$ from 60 to $200{ }^{\circ} \mathrm{C}$, held at $200{ }^{\circ} \mathrm{C}$ for $2 \mathrm{~min}$ then at a rate of $5{ }^{\circ} \mathrm{C} \cdot \mathrm{min}^{-1}$ from 200 to $300{ }^{\circ} \mathrm{C}$ and held at $300{ }^{\circ} \mathrm{C}$ for $15 \mathrm{~min}$. The data was acquired and processed using Chemstation software. The compounds were identified by comparing mass spectra with NIST05 library data.

\section{Results and discussion}

Figure 1 exhibits the total ion chromatogram (TIC) of TDSL sample. In total, 109 organic compounds were detected. 15 kinds of arenes (peak 51, 53, 55, 58, 59, 60, 62, 63, 65, 68, 69, 86, 89 and 92) are listed in table 2.

Table 2 Arenes detected in TDSL with toluene/ethanol

\begin{tabular}{ccc}
\hline peak & compound & relative content $(\%)$ \\
\hline $\mathbf{5 1}$ & 9-ethylphenanthrene & 0.68 \\
$\mathbf{5 3}$ & 1,6,7-trimethylnaphthalene & 0.95 \\
$\mathbf{5 5}$ & 3-methylbiphenyl & 0.38 \\
$\mathbf{5 8}$ & 1,4-diisopropyl-2,5-dimethylbenzene & 0.54 \\
$\mathbf{5 9}$ & 1,2,4,5-tetraethylbenzene & 1.26 \\
$\mathbf{6 0}$ & 4-isopropyl-1,6-dimethylnaphthalene & 0.77 \\
$\mathbf{6 2}$ & 1,3,5-triisopropylbenzene & 0.76 \\
$\mathbf{6 3}$ & 2,3,4,4a,5,6-hexahydro-7-isopropyl-1,4a-dimethylnaphthalene & 1.01 \\
$\mathbf{6 5}$ & 10-sec-butyl-9,10-dihydroanthracene & 0.71 \\
$\mathbf{6 8}$ & 10-allylanthracene & 0.63 \\
$\mathbf{6 9}$ & 1-benzyl-3-ethylbenzene & 0.66 \\
$\mathbf{8 6}$ & 2-ethylanthracene & 0.21 \\
$\mathbf{8 9}$ & 3,6-dimethylphenanthrene & 0.21 \\
$\mathbf{9 1}$ & 7-butyl-1-hexylnaphthalene & 0.26 \\
$\mathbf{9 2}$ & 2,5-dimethylphenanthrene & 0.30 \\
\hline
\end{tabular}

Seeing from table 2, we can find most arenes detected in TDSL were polycyclic aromatic hydrocarbons. Polycyclic aromatic hydrocarbons are ubiquitous for environmental and food contamination. It is a kind of organic compound which has serious harm to health and has a strong carcinogenic and mutagenic properties to human body ${ }^{[4-6]}$. In the process of processing and utilization of coal, these factors such as transportation and combustion, are likely to lead to the release of polycyclic aromatic hydrocarbons in coal to the environment, which has a great impact on the ecological security ${ }^{[7]}$. Therefore, the research on the arenes in Shengli lignite will be an important subject which needs to be further studied. 


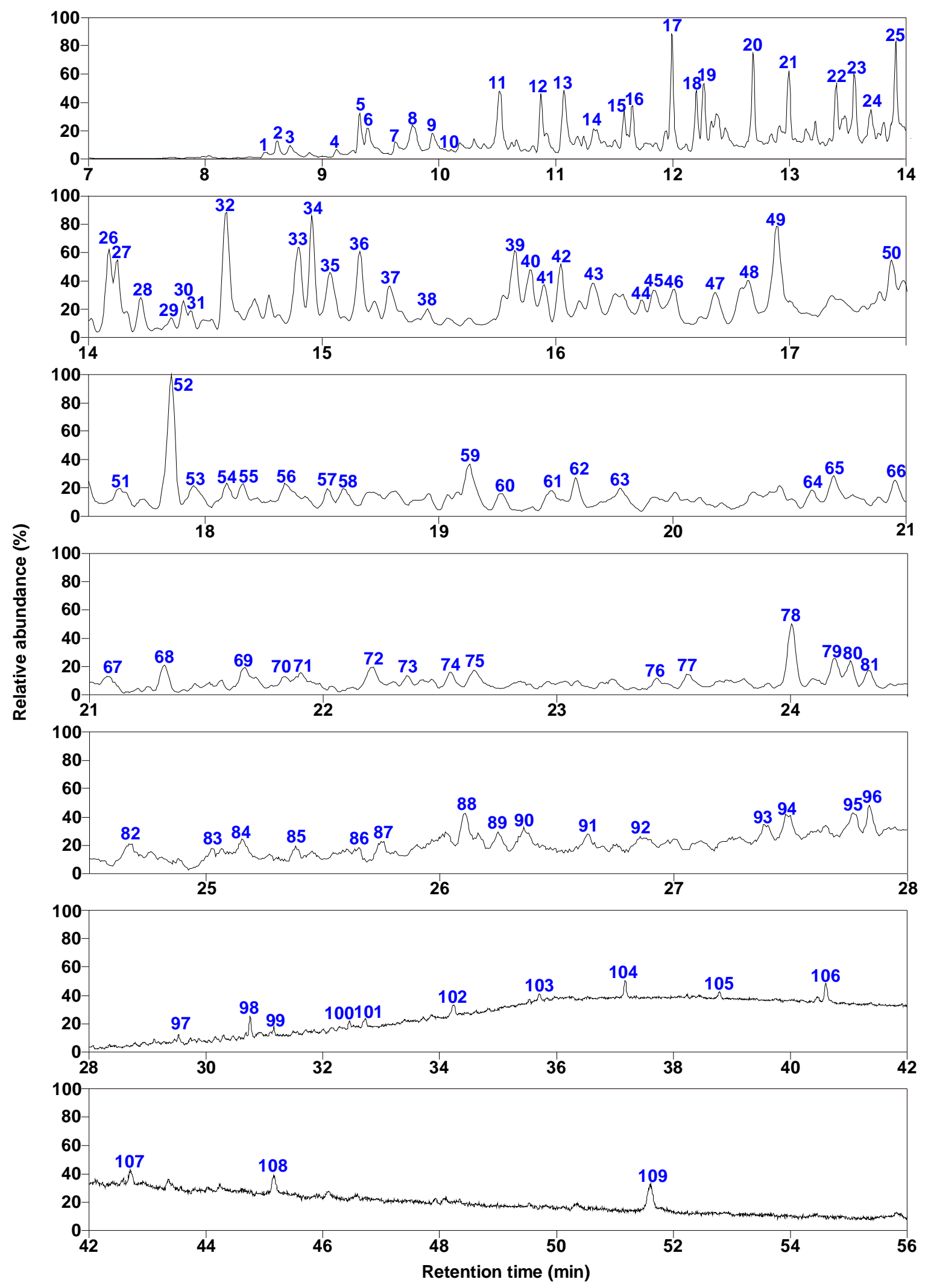

Figure 1 TIC of TDSL with toluene/ethanol

\section{Conclusions}

Study on polycyclic aromatic hydrocarbons in Shengli lignite is the basic stage to obtain high-valued of organic chemicals from lignite, and could provide a basis for further research on the formation, emission and pollution control of polycyclic aromatic hydrocarbons in coal combustion 
and gasification process.

\section{Acknowledgements}

The authors are grateful for financial support from General Program on University Science Research of Jiangsu Province (Grant No. 15KJB480003), Research Project of Xuzhou Institute of Technology (Grant No. XKY2014311), National Natural Science Foundation of China (Grant No. 21472071) and Fund on Key Laboratory of Green Technology of Xuzhou (Grant No. SYS2012009).

\section{References}

[1] Zhenyong Miao, Xin Zhang, Weixin Hu, et al. Coal Technology, 2003, 22(11): 3-5. (In Chinese)

[2] Song C S. Chemicals and Materials from Coal. State of the Art and New Opportunities for Research[C]. In: Li Baoqing, Liu Zhenyu, eds. Prospects for Coal Science in the 21\# century. Taiyuan, 1998: 897-900. (In Chinese)

[3] Song CS, Schobert H H. Fuel, 1996, 75(6): 724-736.

[4] Gaifeng Xue, Chuanzhi $\mathrm{Xu}$, Peng Chen. Journal of Wuhan University of Science and Technology (Natural Science Edition), 2006, 29 (6): 571-573. (In Chinese)

[5] Qihou Chen, Junhe Yang. Fuel and Chemical Processes, 2001, 32(3): 124-126. (In Chinese)

[6] Gaifeng Xue, Ru Xiang, Peng Chen, etal. Journal of Wuhan University of Science and Technology (Natural Science Edition), 2009, 32(1): 36-40. (In Chinese)

[7] Junfei Wei, Jiaqiang Wu, Wenjuan Jiao. Pollution Control Technology, 2008, 21(3): 65-70. (In Chinese) 